\title{
MS41-P01 | Watching Nanodefects GRoW in Si CRystals
}

Magerl, Andreas (University Erlangen-Nürnberg, Erlangen, GER)

Thickness-dependent Pendellösung oscillations as described by the dynamical theory of X-ray diffraction are extremely sensitive to strain fields from defects in a host crystal. Based on this, we initiated a novel approach to study nucleation and growth of oxygen precipitates in moderately $\left(\approx 10^{15} 1 / \mathrm{cm}^{3}\right)$ and highly $\left(\approx 10^{18} 1 / \mathrm{cm}^{3}\right)$ boron doped Czochralski Si crystals in-situ up to $1000^{\circ} \mathrm{C}$. This provides a unique access to monitor continuously the evolution of defects from their very early stages to the long time behavior. The data is interpreted within a diffusion-limited model of growing spherical precipitates with two growth regimes, where an initial diffusion driven mode is followed by a long time precipitation behavior, interpreted as Ostwald ripening. 